\section{SAAAA \\ JOURNAL}

Journal of Archaeology and Fine Arts in Southeast Asia

Published by the SEAMEO Regional Centre for Archaeology and Fine Arts (SPAFA)

\title{
The Singapore National Dance Company: Reminiscences of an Artistic Director
}

\author{
Dr. Francis Yeoh \\ Retired Senior Lecturer, Freelance Lecturer \\ London Studio Centre, BA (Theatre \\ Dance) programme validated by \\ Middlesex University \\ London, United Kingdom \\ francisyeoh13@gmail.com
}

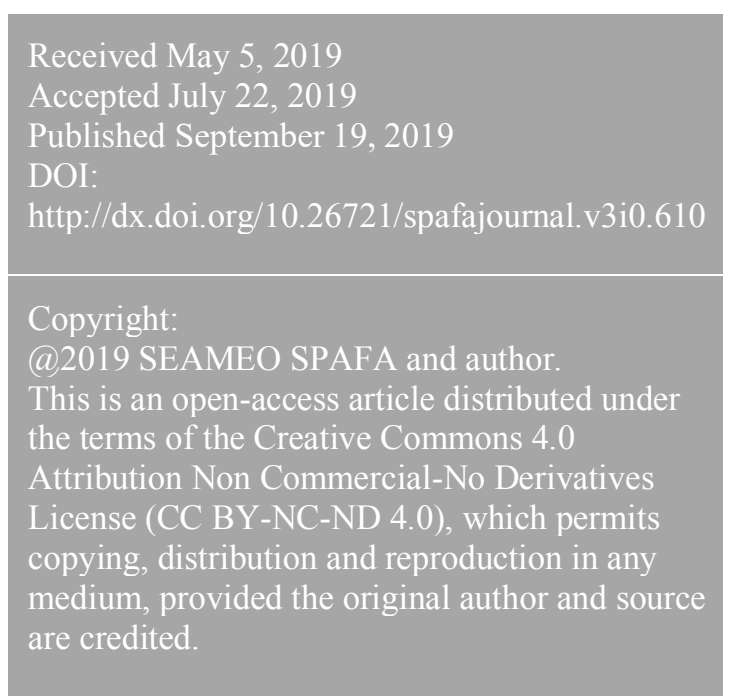

\begin{abstract}
These reminiscences of Francis Yeoh, founding artistic director of The Singapore National Dance Company (1970-1985) is to create a tangible record of the Company's history. Its inaugural overseas performance was launched at the Adelaide Festival in 1972 following an invitation from the South Australian Premier Donald Dunstan. The enormous success of the performances paved the way for the Company to become the island nation's flagship company: embarking as cultural ambassadors in tours that included performances in the Soviet Union (1973 - Moscow, Kharkov and Kurst), Theran, Iran (1974), Seoul, South Korea (1975), Bangkok, Thailand (1976) and Kuala Lumpur, Malaysia (1977). Its history marks an important phase in the island nation's history when it was seeking to establish its national identity and its eventual development as a global city.
\end{abstract}

Keywords: Singapore, Singapore National Dance Company, multicultural dance, national identity 


\section{Introduction}

The ephemeral nature of dance like all the performing arts requires works to be fixed in tangible form. It is, therefore, I believe, my incumbent duty to document the history of the Singapore National Dance Company so that its existence does not fade from memory. I will describe and appraise the many important moments during my tenure as founding artistic director from its formation in 1970 until my departure for London in September 1978.

\section{The Adelaide Festival of the Arts 1972}

The catalyst that triggered the formation of the Singapore National Dance and Theatre Company (later referred to as the Singapore National Dance Company or National Dance Company) was an invitation to Singapore to send a cultural troupe to the 1972 Adelaide Festival from South Australia's Premier Donald Dunstan. This prompted the idea that a cultural troupe must be established to secure a multicultural performance that reflects the special identity of Singapore and is a worthy theatrical presentation at an international event (Figure 1).

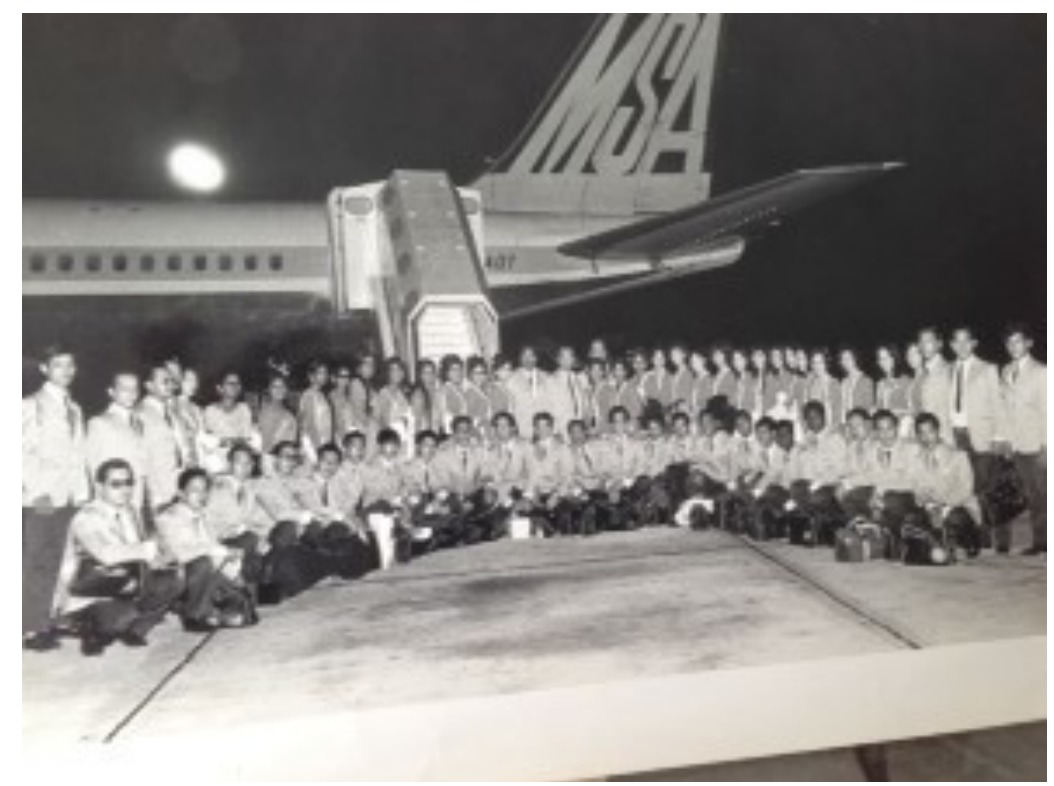

Fig. 1 The Singapore National Dance and Theatre Company at the Adelaide Festival 1972. Source: Francis Yeoh, personal collection from the Ministry of Culture, Singapore.

The Ministry for Culture conducted nationwide auditions to assemble a team of performers that would be able to showcase the cultural diversity of Singapore. A significant factor is that the dancers were amateurs from the major ethnic groups. They were to devote their leisure hours to rehearsing dance works but they had to seek other gainful employment to support themselves and their families. They were from various professions such as lawyers, accountants, radiographer, teachers and civil servants. Their participation was therefore totally driven by their love of dancing and their desire to perform on international platforms. The eventual achievements of the Company must be attributable to supreme effort by all parties involved and the 
Company was afforded enormous support by the Ministry for Culture. The dancers rehearsed for three hours at least three times a week and these were initially conducted at the Extracurricular Centre in Farrer Park but, to their great delight rehearsals were transferred to the Victoria Memorial Hall that had a wooden floor which was ideal.

The prime objective was to create a repertoire of dance works that would legitimise the Company's participation at the Adelaide Festival: it would not only reflect the rich multicultural heritage of the new nation but also ensure the requisite standard of excellence and beauty in performances. It took more than a year of determination and grit by the dancers and the artistic team. The performances by the Company at the Adelaide Festival won much acclaim and its success was reported by news media both in Adelaide and in Singapore. This report from the Singapore National Archives provides a good example of the rapturous reception that the Company enjoyed:

The Singapore cultural troupe to the Adelaide Festival of Arts returned today [14 March 1972]. For two weeks the 67-member troupe, led by parliamentary secretary of the Ministry of Culture Sha'ari Tadin, thrilled Australia audiences with their pulsating music, colourful costumes and multi-racial dances. (Singapore Press Holdings, 1972)

The enormous joy and satisfaction that followed the success of the venture launched the Singapore National Company as the nation's flagship and its role as cultural ambassador began. Personally, as there were many other international companies participating at the Festival, I was overwhelmed by the enormous interest that the Company attracted not only from the audiences but also from the press and television. I was interviewed on television and Premier Donald Dunstan hosted a dinner for Sha' ari Tadin and some members of the Company. One particular heart-warming observation that I encountered was the contention that the Company has raised the profile of Singapore and the publicity generated is worth millions particularly for the tourist trade. As a consequence of this unexpected achievement, I was awarded the Bintang Bakti Masharakat (Public Service Star) at the 1972 National Day Honours list and was also named as one of the top ten Singaporeans by the Singapore's afternoon newspaper New Nation in its review for the year.

\section{Creating a national identity}

The outcome of the success attained at the Adelaide Festival was the recognition that the Singapore National Dance Company has become a national institution. This achievement accords with then-Prime Minister Lee Kuan Yew's determined efforts to forge a spirit of nationalism: he had introduced policies that were firmly based on a multicultural and multiracial outlook with the slogan, 'Unity in Diversity'. The maintenance of the different ethnic art forms on an equal basis is an attempt to sustain not only good relations with its neighbours but also to prevent the recurrence of the racial riots of the sixties that was a major catastrophe at this moment in the nation's history. The ethnic communities were encouraged to continue the maintenance of their traditional dance forms through their cultural associations. This phenomenon sustained the delicate balance between the old and the new. In this regard, the Singapore Tourist Promotion Board adopted the term 'Instant Asia' promoting the 
image of a culture that belongs to the Asian region. During this period, I experienced the profound awareness that the nation's cultural heritage was not only being preserved but it was also being strongly developed by a valiant group of dedicated performers, teachers and choreographers who have worked tirelessly without concern for monetary gain; totally boosted by their unswerving passion for their art form. The mission of the Singapore National Dance Company was not only the preservation of the nation's cultural heritage but also to explore the latest ideas in the creation of its dance repertoire.

My role as the founding artistic director of the Company was therefore, all the more demanding, as it is relentlessly driven by the desire to create a company of evident excellence that fully justifies the status bestowed. The mission was therefore to create a repertoire of works that not only preserved the traditional ethnic dance styles but also, to generate dance works that embrace the crossing of the multi-faceted influences present in the composition of the national company that were handpicked from the best dancers available in the island nation. In this regard, in the programme leaflet accompanying the Singapore National Dance Company's Cultural Exchange tour of the Soviet Union in 1973 (Figure 2), it was stated: "Always jealous of its reputation for high standards of performance, its members have relentlessly adhered to a regular schedule of rehearsals of three times a week, including weekends."”

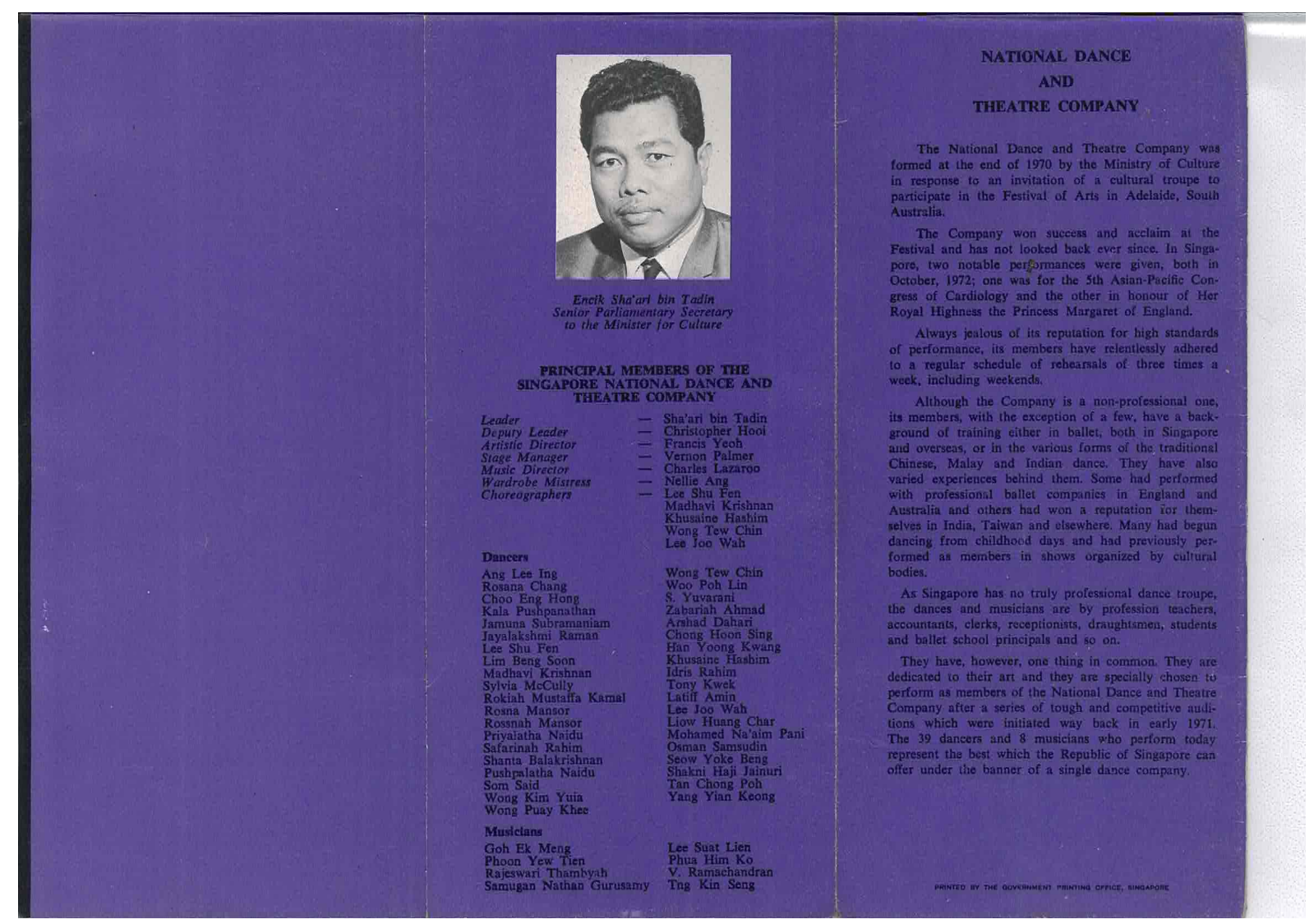

Fig. 2: Programme Leaflet of the Singapore Cultural Mission to the Soviet Union with performances in Moscow, Kharkov and Kursk. Source: Francis Yeoh 
In a press release for the Company's performances at the Victoria Theatre in 1985 it was stated the aim was to "pioneer in introducing composite dances reflecting the multicultural character of Singapore" (Ministry of Culture press release, [1985, unpublished] National Archive of Singapore). The choreographers of the Company were constantly mindful of this vital mission. I would therefore discuss some of the new works created. A favourite among my works is 'Suriram Suite' to music arranged by Singapore composer Charles Lazaroo (Figure 3). The choreography exploited the versatility of the dancers who, although they had specialized in a particular dance style, were able to perform the new work that was a 'fusion' of all their dance styles. 'Harvard Festival' is another work that I am proud of. It was choreographed in 1963 for a Malay Dance Group, Sriwana, and it was screened by Singapore Television. It was restaged for the Company: this work fused Malay dance and ballet movements. Dr Chua Soo Pong (1990) commented on this work: "Amid the movement of cross cultural fertilization, Francis Yeo[h], an amateur ballet dancer trained by the Singapore Ballet Academy in 1963 choreographed a Malay dance called "The Harvest", incorporation balletic steps. The surprising result of the positive reception given by the audience encouraged the choreographers of Sriwana to experiment with more creative choreography."

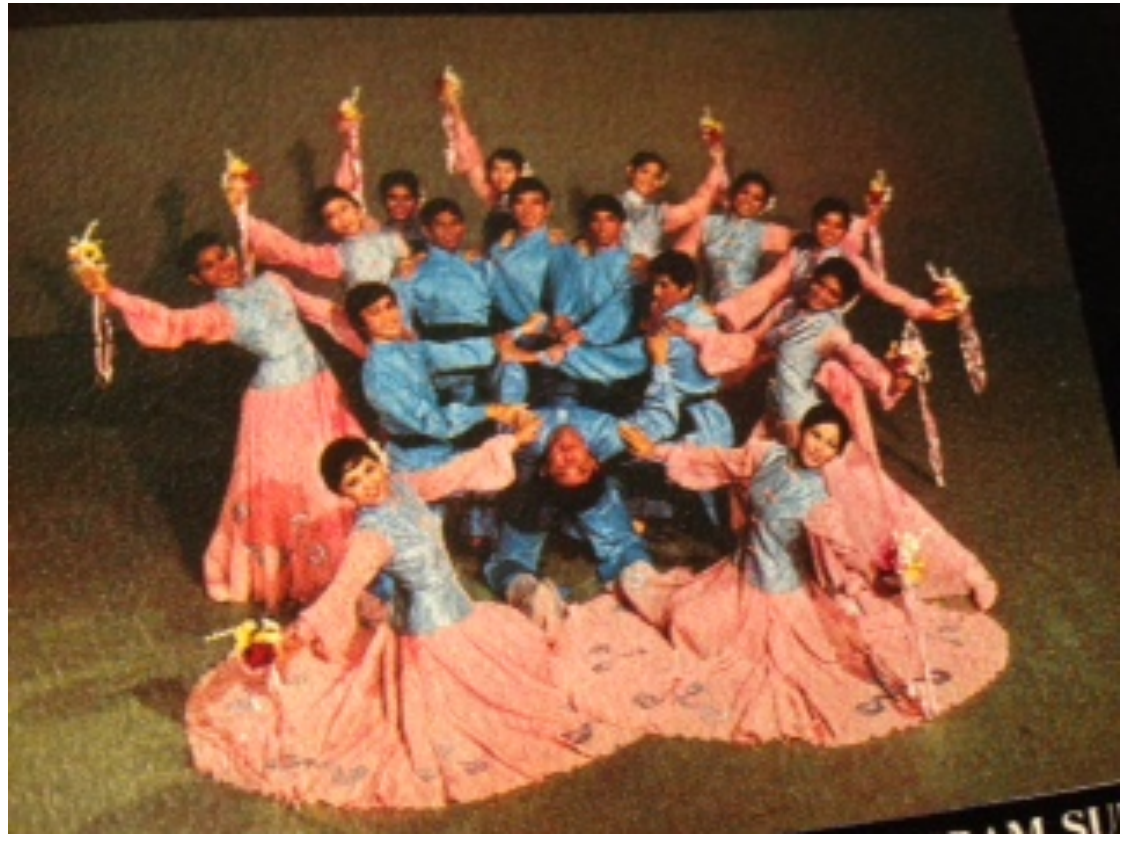

Fig. 3 'Suriram Suite', choreography by Francis Yeoh, music by Charles Lazaroo, Singapore National Dance Company. Source: Francis Yeoh, courtesy of the Ministry of Culture, Singapore

Similarly, Madam Lee Shu Fen dubbed 'Mother of Chinese dance', created 'The Cowherd and the Maiden' employing choreography that assimilated the classical Chinese dance style as well as ballet. Madam Lee trained in Taiwan and Japan in both styles. Notably, the lead role was performed by Sylvia McCully who was trained at the Royal Ballet School, London (1966-1970) and she fully captured the delicate and intricate choreography under the guidance of Madame Lee. Indian dance specialist and recipient of the coveted Singapore Cultural Medallion, Madhavi Krishan, created many narrative works that reflected not only her training in India with renown 
masters: Sri Guru Gopinath Tangamai, (Kathakali dance style) and T V Sundarajan, (Bharatha Natyam) but also her familiarity with Malay and Chinese dance styles. One significant creation was the outcome of her collaboration with Mohd Naim Pani and Wong Tew Chin, in the creation of 'Fisherfolk' in 1976 that exploited the versatility of the dancers.

My artistic vision for the Company was greatly influenced by the example set by Dame Ninette de Valois, the founding artistic director of the Royal Ballet in the UK. I had the privilege to receive personal tutorials, to attend her ballet classes and to be rehearsed by the grande dame of British ballet in the famous classics 'Coppelia' and 'The Sleeping Beauty Act III' for the graduation performances when I was at the Royal Ballet School in 1965. My experiences were further enhanced when I was chosen to perform with the Royal Ballet at the Royal Opera House in their new production of 'Cinderella' by Frederick Ashton during the Christmas season in 1965. I also gained professional dancing experience as a soloist with the Harlequin Ballet on its Arts Council tour of Scotland in 1967; the season informed me of the trials and tribulations encountered by a touring company. Although I had gained enormous experience with the Singapore Ballet under our local teachers, Vernon Martinus, his wife Frances Poh and Soonee Goh, and we had performed successfully in ballet seasons at the Victoria Theatre, I was mindful that I needed to widen my horizons and therefore applied for a British Council grant to study at the Royal Ballet School so as to absorb ideas at an international level My Singapore Ballet Academy male class (we had a strong cohort of men at that period) included Goh Choo San (who attained fame as a choreographer in the US and Europe), Tony Then (Western Theatre Ballet and founder co-director of the Singapore Dance Theatre), and Yang Yee (featured as the Young Soldier [Folkwang Ballet under the name Yeo Siong Leng] in Jooss' ballet Green Table, BBC, 1967, executive director, Singapore television and successful entrepreneur in Hong Kong) and, together in 1963, we successfully passed the Advanced Level exam of the Royal Academy of Dance in Singapore. These learning experiences in the UK shaped my approaches to rehearsing, choreographing and staging the works performed by the Singapore National Dance Company.

I tried to emulate the philosophy adopted by 'Madame' (the affectionate reference to Dame Ninette). Her creation, the Royal Ballet, established is identity through its repertoire. De Valois was acutely aware of the role that the company she was building could play. The blueprint that she had drawn fully appreciated the elements that were necessary in creating a national institution. She was relentless in her pursuit of this aim and her choice of works in the initial years for her company fully reflected this objective. She succeeded in creating a repertoire of works by a 'home team' choreographers in works heavily influenced by 'local' themes and enhanced by designs and music by British artists and composers. She was my ideal as artistic director.

\section{Becoming a flagship institution}

John Pick posited that governments support 'the richest and most sophisticated aspects of the culture', as 'such national investment contributes to the national glory' (Pick, 1986: 152). The Singapore National Dance Company, after its success at the Adelaide Festival in 1972, began to undertake the role of a flagship institution. It undertook not only overseas missions but also, performed for VIPs such as HRH 
Princess Margaret, President Suharto and of course, at National Day Celebrations and Arts Festivals. During the period between 1970 and 1978, while I was artistic director, the Company travelled overseas as cultural ambassadors:

- Australia (Adelaide Festival, March 1972)

- the Soviet Union (cultural exchange programme, performing in Moscow, Kharkov, and Kurst, May \& June1973)

- Thailand (Asian Games Cultural Festival, Bangkok)

- Indonesia (cultural tour of Jakarta, Jogakarta and Bali, October 1974 sponsored by the Singapore Chamber of Commerce)

- a contingent of 14 dancers performed in Iran (7th Asian Games Cultural Programme in Tehran, September 1974)

- Seoul, South Korea (Asian and Pacific Nations Folk Art Festival, September 1975)

- Bangkok, Thailand (Asian Music and Dance Festival, January 1976)

- Kuala Lumpur, Malaysia (9th SEA Games Cultural Festival, November 1977).

My tenure as artistic director, ended in September 1978 after I had led a small contingent from the Company to perform in San Francisco and Los Angeles to mark the inaugural flights of Singapore Airline to these cities, I travelled to London to accept the job of administrator and company secretary offered by my alma mater, the Benesh Institute of Choreology.

\section{Reflection}

The encouraging growth in artistic development of choreographers and dancers is a momentous outcome of the ethos and practices of the Singapore National Dance Company. One major achievement is the creation of original narrative dance works that were inspired by myths and legends that were popular in Singapore. Lee Shu Fen's first major work 'Cowherd and the Maiden' was one of the highlights of the performance at the Adelaide Festival. However, in later years, she created other successful dance dramas such as 'Liang Shan-Po and Shu Ying Tai' (1976), 'Monkey God' (1978) and 'Hua Mulan' (1985). Likewise, Madhavi Krishnan enhanced the repertoire of the Company with dramatic dance works such as 'Basmasura and Hohini' (1976) and 'Meera's Dream' (1985): they were adaptations of the myths of Lord Siva. In recognition for her work, she received the Cultural Medallion in 1980, soon after its establishment the previous year.

The younger members of the Company have also carved their 'spaces' in Singapore's cultural firmament. Two prominent examples are Som Said and Yan Choong Lian. Together with Neila Satiyalingam, they formed Singapore Multi Ethnic Ensemble in 1985 to present programmes for children. They were 'performing on the edge' and extending the borders of their dance styles to engender greater excellence and artistry. That the institutions they have created are flourishing today is testament to the excellence of their artistic visions.

Som Said was prolific as a choreographer and was awarded the Cultural Medallion in 1987 and in 1997, she embarked on a brave project by founding the first professional 
Malay dance company, Sri Warisan Som Said Performing Arts. Som Said's artistic vision totally reflects the ethos adopted by the Singapore National Dance Company (Esplanade - Theatres on the Bay 2012). She declared: "Tradition is not static. When heritage is passed down from generation to generation, it has to keep moving to stay relevant" (Lee 2015). Her dance dramas include 'Singapura Dilanggar Todak', 'Putri Gunung Ledang', and in 2005 her 'Legenda Tun Fatimah' enjoyed enormous success followed by 'Raden Mas' in 2008 that revealed her growing maturity in the unusual treatment of a local Singapore myth.

Yan Choong Lian strengthened her experience with the Company by founding the Yan Choong Lian Dance Troupe in 1988, and subsequently the Dance Ensemble Singapore in 1993. Dance Ensemble Singapore has built up a classical and contemporary repertoire that embraces multi-disciplinary arts forms (DESARTsSingapore 2012). It has become not only an important player in the cultural scene but also a respected educational college.

Another alumni of the Company, Mohammed Na'aim Pani continued to choreograph and teach. Dr. Chua Soo Pong (1990) observed: "Mohd Na'aim Pani, inspired by performances seen at the Asean Festival, choreographed a dance drama, 'Arjuna', for his newly formed dance group, Rina. It was premiered during the first Singapore Festival of Dance, presented by the National Theatre Trust in March 1982."

In order to appreciate these amazing developments, it is imperative that they are considered within the context of the changes in political and economic policies in the new nation. Singapore was granted self-government by the British in 1959. In 1963 it joined the newly created Federation of Malaysia. However, in 1965, differences in political visions led to Singapore's separation from Malaysia. Within a few decades the island nation had achieved remarkable growth with its highly motivated and inventive economic development plans. The cultural renaissance that began in the $90 \mathrm{~s}$ and the aspiration to become a global city launched many flagship companies such as the National Symphony Orchestra was formed in 1979; the Ballet Group of the National Dance Company, created in 1986 was expanded to become Singapore Dance Theatre two years later with artistic directors Goh Soo Khim and Tony Then and the Singapore Chinese Orchestra that was formed in 1996. Furthermore, the auspicious formation of the National Arts Council in 1991 was another major milestone. In 1996, Professor Tommy Koh, the founding chairman of the National Arts Council, voiced his ambition "to nurture our flagship companies so that the standard of their performances will make them the best in the region, so that people will fly in not only to catch an imported performance but to see Singapore performances" (Koh 1996: 19).

The growth of dance institutions is a direct consequence of the seismic change in attitude toward the arts in Singapore and to the continued artistic growth of dance artists. The fact that the cultural milieu has vastly changed is a result of the Renaissance Singapore programme - the outcome of the valuable encouragement extended to dance artists by the Arts Council through its excellent programme of financial assistance and provision of 'housing' (Yeoh, 2006). Furthermore, this vigorous environment is allowing greater avenues for the creation of Singapore identity in the art form of dance. I will quote Professor Tommy Koh to conclude this 
retrospective on the Singapore National Dance Company: "If it is our ambition to be a leading city of the world, then we must have the cultural life which a leading city affords its citizens, residents and visitors."

\section{Bibliography}

Chua S P (1990) The Dynamics Of The Singapore Malay Dance: A Preliminary Study. SPAFA Digest 11(1): 44-52. Available at: www.spafajournal.org/index.php/spafadigest/article/download/532/527 (accessed 17 May 2019).

DESARTsSingapore (2012) DES Opening Final.mp4. Available at: https://www.youtube.com/watch? $\mathrm{v}=\mathrm{x} 2$ YPmzpugys (accessed 17 May 2019)

Esplanade - Theatres on the Bay (2012) TributeSG - Som Said. Available at https://www.youtube.com/watch?v=fKshrfbhbWY (accessed 17 May 2019).

Koh B S (1996) Interview with Professor Tommy Koh in The Arts in Singapore. Singapore: National Arts Council and Accent Communications. GS SEARCH

Lee, V (2015) Malay Dancing Queen. Straits Times, 23 February. Available at: https://www.straitstimes.com/lifestyle/.../malay-dancing-queen-sommohamed-said (accessed 17 March 2019).

Ministry of Community Development (5 September 1985) Public performances of the National Dance Company [Unpublished press release] Singapore: National Archives of Singapore. GS SEARCH

Ministry of Information and the Arts. (2000). Renaissance City Report - Culture and the Arts in Renaissance Singapore. Singapore: Ministry of Information and the Arts. GS SEARCH

Pick, J (1986) Models for Government Subvention. In: Managing the Arts? The British Experience. London: Rhinegold, 148-167. GS SEARCH

Singapore Press Holdings (1972) PCD0409 - 0068 [Image number]. Singapore: National Archives of Singapore. Available at http://www.nas.gov.sg/archivesonline/photographs/record-details/a86dc1f41162-11e3-83d5-0050568939ad (accessed 30 August 2019).

Yeoh, F (2006) Nationalism in Dance: The Singapore Perspective. Available at: www.academia.edu/13266165/Nationalism_in_Dance_The_Singapore_Perspe ctive (accessed 18 May 2019). 